\title{
Comparative analysis of the mating system of the rare woodland shrub Daviesia suaveolens and its common congener $D$. mimosoides
}

\author{
A. G. YOUNG* \& A. H. D. BROWN \\ Centre for Plant Biodiversity Research, CSIRO Plant Industry, GPO Box 1600, Canberra, ACT 2601, Australia
}

\begin{abstract}
Controlled pollinations and allozyme markers were used to compare mating system parameters among three populations of the rare woodland shrub Daviesia suaveolens Crisp. and five populations of its common relative $D$. mimosoides $\mathrm{R}$. Br. Pollination results show that both species require a vector to facilitate pollination and have strong self-incompatibility mechanisms. Multilocus estimates of outcrossing rates confirm this, with all populations being highly outcrossed $\left(D\right.$. suaveolens $t_{\mathrm{m}}=0.78-1.0 ; D$. mimosoides $\left.t_{\mathrm{m}}=0.71-0.96\right)$. Smaller and less dense $D$. mimosoides populations had higher correlations of outcrossed paternity than larger ones. The divergence of pollen pool allele frequencies from population frequencies was greater in smaller populations than in larger ones, in keeping with a lower effective size of the male source. Regression analyses generally failed to show effects of either plant size or local flowering environment on estimates of single-plant outcrossing rates. Most variation in these rates probably reflects the combined effects of sampling error, correlated mating and the influence of marker diversity on outcross detectability.
\end{abstract}

Keywords: allozyme, correlated paternity, Leguminosae, mating system, rare shrub.

\section{Introduction}

Knowledge of the mating system is useful in planning the management of plant species for conservation for several reasons. Mating systems are a primary determinant of how genetic diversity is distributed among individuals and populations within a species. As such, they influence how germplasm collections should be made for ex situ conservation (Brown \& Marshall, 1995) and which populations should be given priority for in situ efforts (Frankel et al., 1995). The mating system also delimits demographic responses to situations in which opportunities for outcrossed sexual reproduction are limited, such as population bottlenecks caused by colonization events or habitat fragmentation, e.g. DeMauro (1993). In combination with ploidy level and mode of gene expression, it also affects evolutionary responses to such situations. For example, the mating system influences to what degree small populations can purge genetic load through inbreeding coupled with selection.

*Correspondence. E-mail: a.young@pican.pi.csiro.au
Allozyme studies have found that plants exhibit a wide range of outcrossing rates. Some of this variation results from the ecological characteristics of different populations. For example, studies of both natural and artificial populations of insect-pollinated plants have demonstrated correlations between the density of flowering individuals and population outcrossing rate that probably relate to the effects of plant density on pollinator movements, e.g. Ellstrand et al. (1978); Watkins \& Levin (1990); Murawski et al. (1994) and Karron et al. (1995).

It has also been argued that the local abundance of a species is linked to its mating system, with the frequency of self-compatibility likely to be higher among locally rare species than among species that exist in large populations. The main reasoning behind this line of thought, initially proposed by Baker (1955) and Stebbins (1957) and expanded by Karron $(1989,1991)$, is that when population sizes are small or fluctuate, self-compatible individuals will be favoured by selection arising from reduced opportunities for outcrossing in the face of limited numbers of potential mates, or possibly reduced pollinator activity. Small populations may also repre- 
sent favourable situations for the evolution of selfcompatibility if genetic drift reduces the frequency of deleterious genes, as this will lower the fitness costs associated with selfing (Schemske \& Lande, 1985; Karron, 1989).

In this study, controlled pollinations and allozyme markers were used to investigate the mating systems of two understorey shrub species: Daviesia suaveolens Crisp., which is rare, and its common and widespread relative $D$. mimosoides $\mathrm{R}$. Br. The objectives were: (i) to assess whether there are differences in mating systems between the two species that may relate to their different patterns of abundance; (ii) to determine if population size, isolation or density influence mating system parameters of populations within each species; (iii) to investigate the effects of local flowering environment and maternal plant size on single-plant female outcrossing rates; and (iv) to determine any implications the mating system may have for managing Daviesia suaveolens for conservation.

\section{Materials and methods}

Study species

Daviesia suaveolens and D. mimosoides are leguminous shrubs forming part of the D. latifolia group within the subtribe Mirbelieae (Fabaceae) (Crisp, 1991). Both species are pollinated by generalist bee pollinators (Apis mellifera and Lasioglossum sp.). Daviesia suaveolens is rare and has a narrow geographical distribution extending some $115 \mathrm{~km}$ along the southern tablelands of New South Wales. It is known from only 10 geographically isolated populations found almost exclusively on exposed rocky ridges between 800 and $1200 \mathrm{~m}$ high, where it is associated with eucalypt-dominated open woodlands. Populations range in size from 39 to $>10000$ flowering plants. In contrast, D. mimosoides is a widespread and common species with a broad geographical distribution extending from southeastern Queensland through eastern New South Wales into Victoria. Daviesia mimosoides is known from hundreds of populations occupying a wide range of habitats from sea level to $1500 \mathrm{~m}$. It is associated with eucalypt woodlands, coastal heaths and acacia shrublands. Populations are generally large, often exceeding 10000 flowering plants and extending continuously for several kilometres as the dominant species in the shrub layer.

Both $D$. suaveolens and $D$. mimosoides exhibit high levels of allozyme diversity at both the species and the population levels (Young \& Brown, 1996).
However, they differ in the degree of genetic divergence of their populations, with populations of the rare species being three times as genetically differentiated from each other as those of the common species over the same spatial scale.

\section{Controlled pollination}

The flowers on five plants within a single population of each species were manipulated to assess their potential for self-fertilization and agamospermy. Both species flower prolifically during spring. Flowers are hermaphrodite with 10 anthers and a single style leading to an ovary containing two ovules. In preliminary experiments, any attempt at emasculation resulted in flower abortion, so controlled outcrosses could not be performed. Therefore, three pollination treatments were imposed on each plant. (1) Open pollinated flowers were tagged and left unmanipulated until pod formation began, at which point they were bagged to recover seed. (2) Selfed - flowers were tagged and bagged at the bud stage to exclude insect pollinators. When flowers were open and anthers had begun to dehisce, bags were removed and anthers were rubbed against the receptive stigma. Flowers were then rebagged for seed recovery. (3) Pollinator-excluded - flowers were bagged at the bud stage to exclude insect pollinators and left bagged until seed recovery. Pods were recovered from all treatments approximately 6 weeks after flowering had finished, and filled seeds were counted. Differences in the percentage of seed set among treatments within a species and between species were assessed using two-way ANOvA on ranked data.

\section{Seed sampling and starch gel electrophoresis}

Samples of between 14 and 16 open-pollinated seed, each from a separate fruit, were collected from 14 or 15 plants within each of three populations of $D$. suaveolens ranging in size from 39 to $>10000$ flowering plants, and five populations of D. mimosoides ranging in size from 145 to $>40000$ flowering plants (see Table 2). The exception to this was the D. mimosoides population at Omeo, from which seed was only collected from five plants. In populations of more than 1000 flowering individuals, plants were sampled randomly along transects that were long enough to encounter 250 plants. In smaller populations, plants were sampled randomly from the whole population.

Seeds were nicked and soaked in water for $6 \mathrm{~h}$ before being germinated for $24 \mathrm{~h}$ on moist filter 
paper. Seed coats were removed, and entire seeds were ground in 3-4 drops of extraction buffer: $0.05 \mathrm{M}$ potassium phosphate buffer ( $\mathrm{pH} 7.0$ ) and $1 \mathrm{mg} \mathrm{mL}^{-1}$ dithiothreitol-DDT. Samples were absorbed onto filter paper wicks and subjected to horizontal starch gel electrophoresis according to Young \& Brown (1996). Four putative allozyme loci for three enzymes were resolved for both species using a morpholine-citrate buffer system at $\mathrm{pH}$ 6.1. These were isocitrate dehydrogenase (IDH) EC 1.1.1.41 (one locus), phosphogluconate dehydrogenase (PGD) EC 1.1.1.43 (two loci) and shikimate dehydrogenase (SDH) EC 1.1.1.25 (one locus). For the two smaller $D$. suaveolens populations, low numbers of alleles and skewed allele frequency distributions at the two PGD loci initially resulted in high variances for estimates of mating system parameters. For these two populations, data from an additional four loci: aconitase (ACO) EC 4.2.1.3 (one locus), malate dehydrogenase (MDH) EC 1.1.1.37 (one locus) and phosphoglucomutase (PGM) EC 5.4.2.2 (two loci) were obtained using a histidine buffer system at $\mathrm{pH}$ 8.0.

\section{Estimation of mating system parameters using allozyme markers}

Maximum likelihood estimates of single-locus $\left(t_{\mathrm{s}}\right)$ and multilocus $\left(t_{\mathrm{m}}\right)$ outcrossing rates were made according to the mixed-mating model of Brown \& Allard (1970) with maternal genotypes being inferred from progeny arrays. Correlation of outcrossed paternity $\left(r_{\mathrm{p}}\right)$ was also estimated following Ritland's (1989) sibling-pair model. In this model, $r_{\mathrm{p}}$ is the probability that two individuals drawn at random from the same progeny array are full-sibs. All parameters were calculated using the computer program MLTR version 0.9 (Ritland, 1994). MLTR is an extension of the program by Ritland \& Jain (1981) allowing up to eight alleles per locus, which meant that all allelic information could be used in the estimation procedures. Standard errors for population estimates of $t_{\mathrm{s}}, t_{\mathrm{m}}$ and $r_{\mathrm{p}}$ were based on 500 bootstraps with resampling among maternal plants. Burrows's composite measure of linkage disequilibria $\left(\Delta_{A B}\right)$ was calculated for all possible pairs of loci within populations with $\chi^{2}$ - tests for significance according to Weir (1990) using the computer package POPGENE (Yeh \& Boyle, 1997).

The extent of divergence between the estimates of allele frequencies in the pollen pool $\left\{y_{i j}: i=1, \ldots\right.$, $\left.k_{j}: j=1, \ldots, l\right\}$ (where $l$ denotes the number of polymorphic marker loci in a population and $k_{j}$ is the number of alleles at the $j$ th locus) and their corresponding estimates in the population $\left\{x_{i j}\right\}$ was measured using $F$-statistics. According to the method of Waples (1989), the Nei and Tajima estimator $\left(F_{\mathrm{c}}\right)$ was computed as:

$F_{\mathrm{c}}=\Sigma_{j i}\left[\left(x_{i j}-y_{i j}\right)^{2} /\left\{\left(x_{i j}+y_{i j}\right) / 2-x_{i j} y_{i j}\right\}\right] / \Sigma_{j i} k_{j}$ and the Pollak estimator $\left(F_{\mathrm{k}}\right)$ as:

$F_{\mathrm{k}}=\Sigma_{j i} 2\left(x_{i j}-y_{i j}\right)^{2} /\left(x_{i j}+y_{i j}\right) / \Sigma_{j i}\left(k_{j}-1\right)$.

The values for $\left\{x_{i j}\right\}$ were those from a previous sample from these same populations (Young \& Brown, 1996) and were based on a larger sample of maternal plants. Linear regression was used to examine the dependence of $F_{\mathrm{c}}$ and $F_{\mathrm{k}}$ on the log of population size.

MLTR was also used to estimate single-plant multilocus outcrossing rates $\left(t_{\mathrm{ms}}\right)$ with standard errors based on 100 bootstraps with resampling among progeny. Both maternal genotype and the numbers and frequencies of alleles at marker loci within a population affect the detectability of outcross events (Adams, 1992). To examine the influence of maternal genotype on the single-plant outcrossing rates, the $t_{\mathrm{ms}}$ estimates and their associated variances were regressed against maternal heterozygosity $\left(H_{\mathrm{o}}\right)$ both within populations and across populations within species. To assess the effect of marker locus variability available within a population on $t_{\mathrm{ms}}$ estimates, the population means of $t_{\mathrm{ms}}$ and their variances were regressed against population gene diversity $\left(H_{\mathrm{e}}\right)$, which reflects both the number and the relative frequencies of alleles within a population. Populations of both species were pooled to increase the sample size for this analysis.

\section{Population characteristics and local flowering environment}

For populations of fewer than 1000 flowering plants, population size and density were determined by counting all flowering plants and measuring population area. For populations larger than this, ten $10 \times 10 \mathrm{~m}$ plots were distributed randomly along the line transect used to sample maternal plants, and these were used to assess the density of flowering individuals. Mean density estimates were multiplied by population area to give estimates of overall population size.

The size of maternal plants was measured by stem diameter for D. suaveolens and both stem diameter and height for $D$. mimosoides. The local flowering environment for each plant was characterized by counting the number of flowering plants within a $10-\mathrm{m}$ radius of the plant's main stem and by measuring the distance to its nearest flowering neighbour. 
Multiple stepwise linear regression was used to investigate relationships between stem diameter, height (D. mimosoides only), flowering density within $10 \mathrm{~m}$ and distance to the nearest flowering neighbour as independent variables, and multilocus estimates of single-plant outcrossing rates as the dependent variable. The $D$. mimosoides Omeo population was excluded from these analyses because of the low numbers of maternal plants sampled. The $D$. mimosoides Boomanoomana population was excluded from the analysis of the effects of flowering density within $10 \mathrm{~m}$, as this variable was not measured for that population.

\section{Results}

\section{Controlled pollination}

The percentage seed-set differed significantly among the three pollination treatments for both $D$. suaveolens and D. mimosoides (among-treatment $F_{2,24}=17.5, P<0.0001$ ) (Table 1$)$. In both species, only open-pollinated flowers exhibited appreciable seed-set, with 7.5 per cent of open-pollinated $D$. suaveolens flowers and 8.9 per cent of open-polli-

Table 1 Percentage seed-set (number of flowers treated) from controlled pollinations in the Daviesia suaveolens Monga population and the D. mimosoides Bull's Head population

\begin{tabular}{|c|c|c|c|c|}
\hline & \multicolumn{4}{|c|}{ Pollination treatment } \\
\hline & Open & Selfed & & $\begin{array}{l}\text { llinators } \\
\text { xcluded }\end{array}$ \\
\hline \multicolumn{5}{|c|}{ D. suaveolens } \\
\hline \multicolumn{5}{|l|}{ Plant } \\
\hline 291 & $2.3(129)$ & $0 \quad(64)$ & 0 & $(365)$ \\
\hline 294 & $2(348)$ & $0 \quad(94)$ & 0 & $(336)$ \\
\hline 490 & $20.4(108)$ & $0 \quad(104)$ & 0 & $(175)$ \\
\hline 553 & $8.3(133)$ & $1.4(74)$ & 0 & $(160)$ \\
\hline 554 & $13.3(180)$ & $0 \quad(104)$ & 0 & $(440)$ \\
\hline Mean & $7.5(898)^{\mathrm{a}}$ & $0.2(440)^{\mathrm{b}}$ & 0 & $(1476)^{b}$ \\
\hline \multicolumn{5}{|c|}{ D. mimosoides } \\
\hline \multicolumn{5}{|c|}{ Plant } \\
\hline 288 & $9.6(83)$ & $1.8(55)$ & 0 & $(62)$ \\
\hline 290 & $11.0(118)$ & $0 \quad(41)$ & 0 & $(83)$ \\
\hline 295 & $0 \quad(108)$ & (49) & 0 & $(116)$ \\
\hline 298 & $0 \quad(96)$ & $0 \quad(30)$ & 0 & (63) \\
\hline 299 & $22.0(113)$ & $1.5(66)$ & 0 & $(50)$ \\
\hline Mean & $8.9(518)^{\mathrm{a}}$ & $0.8(241)^{\mathrm{b}}$ & 0 & $(374)^{\mathrm{b}}$ \\
\hline
\end{tabular}

Means with the same letter (a or b) are not significantly different at $P<0.05$. nated $D$. mimosoides flowers giving rise to seeds. Very few selfed flowers produced seeds $(0.2$ per cent of flowers for $D$. suaveolens and 0.8 per cent of flowers for $D$. mimosoides, and pollinator-excluded flowers failed to produce any seed in either species. Differences in seed-set between the two species within treatments and the interaction between species and treatment were not significant.

\section{Population outcrossing rates and outcrossed paternal correlations}

No consistent pairwise associations among the loci were evident in either species from estimates of Burrows's $\Delta_{A B}$. Therefore, all loci were retained for estimation of mating system parameters. The multilocus outcrossing rates for $D$. suaveolens were high (Table 2) with only Araluen, the largest and by far the most dense of the three populations, having a rate significantly less than one $\left(t_{\mathrm{m}}=0.78\right)$. Two of the five $D$. mimosoides populations had multilocus outcrossing rates less than one (Table 2). The first of these was the large dense population at Bull's Head $\left(t_{\mathrm{m}}=0.83\right)$; the second, Boomanoomana $\left(t_{\mathrm{m}}=0.71\right)$, is a very small, sparse and extremely isolated population on the western edge of the range of the species. Averaged across populations, the species difference in multilocus outcrossing rate was not significant $(P>0.70)$, despite the large differences in population sizes and densities between $D$. suaveolens and $D$. mimosoides. Differences between multilocus and mean single-locus outcrossing rates were negligible for all populations of both species (Table 2).

The correlations of outcrossed paternity for the three $D$. suaveolens populations were moderate, with the smallest and least dense population, Milo Road, having the highest value $\left(r_{\mathrm{p}}=0.40\right)$. However, only the value for the largest population, Araluen $\left(r_{\mathrm{p}}=0.28\right)$, was significantly greater than zero (Table $2)$. The range of correlations for the $D$. mimosoides populations was less than that for $D$. suaveolens $\left(r_{\mathrm{p}}=0.12-0.32\right)$, and none was significantly greater than zero (Table 2). Nevertheless, the two smaller, less dense and more isolated populations of this species had the higher values of $r_{\mathrm{p}}\left(\right.$ Omeo $r_{\mathrm{p}}=0.32$ and Boomanoomana $r_{\mathrm{p}}=0.28$ ), suggesting a relationship between these two population characteristics and the degree of correlated paternity. There were marginally significant negative relationships between the log of population size and the degree of divergence between population and pollen allele frequencies as assessed by $F_{\mathrm{c}}\left(R^{2}=0.48, P<0.06\right)$ and $F_{\mathrm{k}}\left(R^{2}=0.46, P<0.06\right)$ (Fig. 1 , only the results for $F_{\mathrm{c}}$ are presented; Table 3$)$. 
Table 2 Population size, density and estimates of multilocus outcrossing rates $\left(t_{\mathrm{m}}\right)$, and outcrossed paternal correlation $\left(r_{\mathrm{p}}\right)$

\begin{tabular}{|c|c|c|c|c|c|}
\hline & $\begin{array}{l}\text { Number of } \\
\text { flowering plants }\end{array}$ & $\begin{array}{l}\text { Density of } \\
\text { flowering plants } 100 \mathrm{~m}^{-2}\end{array}$ & $t_{\mathrm{m}}(\mathrm{SE})$ & $t_{\mathrm{m}}-t_{\mathrm{s}}(\mathrm{SE})$ & $r_{\mathrm{p}}(\mathrm{SE})$ \\
\hline \multicolumn{6}{|l|}{ Daviesia suaveolens } \\
\hline Araluen & $>10000^{\mathrm{a}}$ & $7.5(2.2)^{\mathrm{a}}$ & $0.78(0.10)^{\mathrm{b}}$ & $-0.05(0.05)$ & $0.28(0.12)^{\mathrm{c}}$ \\
\hline Monga & 308 & 0.8 & $0.94(0.04)$ & $0(0.02)$ & $0.08(0.07)$ \\
\hline Milo Road & 39 & 0.2 & $1.00(0.29)$ & $-0.06(0.18)$ & $0.40(0.31)$ \\
\hline Brindabella & $>40000^{\mathrm{a}}$ & $73.8(8.5)^{\mathrm{a}}$ & $0.96(0.03)$ & $0.05(0.02)$ & $0.14(0.09)$ \\
\hline Bull's Head & $>40000^{\mathrm{a}}$ & $46.5(4.6)^{\mathrm{a}}$ & $0.83(0.07)^{\mathrm{b}}$ & $0.01(0.03)$ & $0.12(0.11)$ \\
\hline Nungatta & $>30000^{\mathrm{a}}$ & $71.3(3.9)^{\mathrm{a}}$ & $0.95(0.04)$ & $0.03(0.02)$ & $0.14(0.16)$ \\
\hline Omeo & $>5000^{\mathrm{a}}$ & $8.9(5.6)^{\mathrm{a}}$ & $0.85(0.14)$ & $-0.02(0.07)$ & $0.32(0.41)$ \\
\hline Boomanoomana & 145 & 1.2 & $0.71(0.09)^{\mathrm{b}}$ & $0.04(0.02)$ & $0.28(0.29)$ \\
\hline
\end{tabular}

${ }^{\mathrm{a}}$ Estimates based on plots. ${ }^{\mathrm{b}} t_{\mathrm{m}}$ significantly less than 1 at $P<0.05 .{ }^{\mathrm{c}} \mathrm{r}_{\mathrm{p}}$ significantly greater than zero at $P<0.05$.

\section{Single-plant outcrossing rates}

Single-plant outcrossing rates were highly variable for both species, with $t_{\mathrm{ms}}$ ranging from 0 to 1 in $D$. suaveolens and from 0.07 to 1 in D. mimosoides. The means of these rates for the two species were similar, but the variance for $D$. suaveolens $\left(\sigma^{2}=0.11\right)$ was significantly greater than that for $D$. mimosoides $\quad\left(\sigma^{2}=0.06\right) \quad\left(F_{34,64}=1.90, \quad P<0.05\right)$,

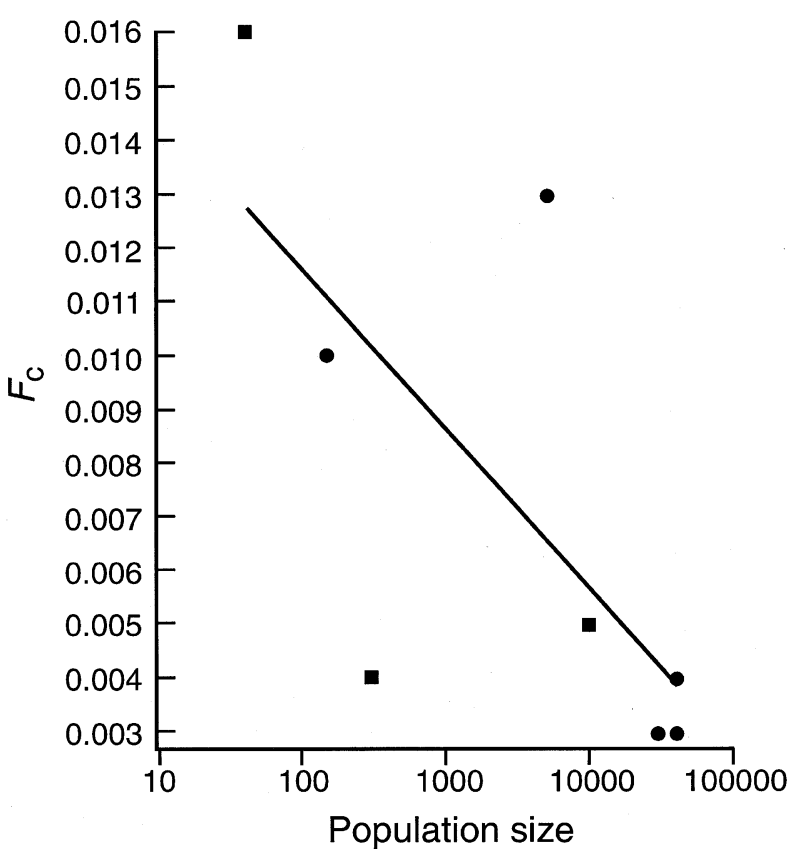

Fig. 1 Relationship between log of population size (number of flowering plants) and the Nei and Tajima estimator $\left(F_{\mathrm{c}}\right)$ of divergence between population and pollen allele frequencies. $R^{2}=0.48, P<0.06$. Daviesia suaveolens; $\bullet, D$. mimosoides. reflecting a flatter frequency distribution of $t_{\mathrm{ms}}$-values for the rare species (Fig. 2). Within populations, stepwise regressions revealed only a single significant relationship between $t_{\mathrm{ms}}$ and the measures of maternal plant size (height, stem diameter) and local flowering environment (number of flowering plants within $10 \mathrm{~m}$, distance to nearest flowering neighbour). This was a weak positive relationship between plant height and outcrossing rate in the $D$. mimosoides Boomanoomana population $\left(R^{2}=0.37\right.$, $P<0.05$; Fig. 3). However, as some 32 tests were conducted, this particular result could have arisen by chance alone. When data from all populations for each species were pooled, no relationships were detected for either species.

There were no significant relationships between maternal heterozygosity at marker loci and either single-plant outcrossing rates or their variances at the population or species levels. Similarly, there was no relationship between population gene diversity and mean $t_{\mathrm{ms}}$ (Table 3). However, there was a marginally significant negative relationship between gene diversity and the magnitude of the variance of $t_{\mathrm{ms}}$ estimates within a population $\left(R^{2}=0.45\right.$, $P=0.07)$. That is, populations with low gene diversity had large variances of $t_{\mathrm{ms}}$.

\section{Discussion}

For both D. suaveolens and D. mimosoides, enforced self-pollination gave fewer seed than open pollination, implying that both species are self-incompatible. However, that seed was set on plants 553 ( $D$. suaveolens) and 288 and 299 (D. mimosoides) after selfing shows that self-fertilization is tolerated occasionally. The prevalence of outcrossing is reflected in

(C) The Genetical Society of Great Britain, Heredity, 80, 374-381. 
Table 3 Mean and variance of multilocus single-plant outcrossing rates $\left(t_{\mathrm{ms}}\right)$ in relation to the average gene diversity for the marker loci and $F$-statistics measuring the divergence between pollen and population allele frequencies $\left(F_{\mathrm{c}}\right.$ is the Nei and Tajima estimator and $F_{\mathrm{k}}$ is the Pollak estimator)

\begin{tabular}{|c|c|c|c|c|c|}
\hline & \multirow{2}{*}{$\begin{array}{c}\text { Gene diversity } \\
\left(H_{\mathrm{e}}\right)\end{array}$} & \multicolumn{2}{|c|}{ Single-plant outcrossing rate $\left(t_{\mathrm{ms}}\right)$} & \multicolumn{2}{|c|}{ Pollen divergence } \\
\hline & & Mean & Variance & $\left(F_{\mathrm{c}}\right)$ & $\left(F_{\mathrm{k}}\right)$ \\
\hline \multicolumn{6}{|l|}{ Daviesia suaveolens } \\
\hline Araluen & 0.23 & 0.40 & 0.09 & 0.005 & 0.009 \\
\hline Monga & 0.32 & 0.83 & 0.06 & 0.004 & 0.004 \\
\hline Milo Road & 0.29 & 0.80 & 0.05 & 0.016 & 0.021 \\
\hline Mean (SE) & $0.28(0.03)$ & $0.64^{\mathrm{a}}$ & $0.11^{\mathrm{a}}$ & $0.008(0.004)$ & $0.011(0.005)$ \\
\hline \multicolumn{6}{|l|}{ D. mimosoides } \\
\hline Brindabella & 0.42 & 0.80 & 0.03 & 0.004 & 0.004 \\
\hline Bull's Head & 0.36 & 0.68 & 0.05 & 0.003 & 0.006 \\
\hline Nungatta & 0.42 & 0.78 & 0.06 & 0.003 & 0.004 \\
\hline Omeo & 0.45 & 0.70 & 0.05 & 0.013 & 0.016 \\
\hline Boomanoomana & 0.38 & 0.57 & 0.06 & 0.010 & 0.015 \\
\hline Mean (SE) & $0.41(0.02)$ & $0.70^{\mathrm{a}}$ & $0.06^{\mathrm{a}}$ & $0.007(0.002)$ & $0.009(0.004)$ \\
\hline
\end{tabular}

${ }^{a}$ Estimates based on pooled population data.

the multilocus estimates of outcrossing rate. These show little evidence of selfing in populations of either species, despite the large differences in their geographical range and the abundance, size and isolation of their populations. Based on the similarities between single and multilocus outcrossing rates, it also seems that biparental inbreeding is negligible.

Studies of several other species have shown that genetic self-incompatibility mechanisms can be maintained in very rare plants, e.g. Les et al. (1991) and DeMauro (1993). There are several possible reasons why $D$. suaveolens shows no evidence of an evolutionary shift towards selfing. First, the lack of seed-set from the pollinator-excluded treatments on plant 553, which is at least partially self-compatible, suggests that a pollen vector is required to achieve pollination. This could have constrained the evolution of self-compatibility, as visitation by pollinators will generally involve some chance of transfer of outcross pollen. Secondly, the low level of seed-set when selfing is successful may confer too small an advantage for selection to act on. Thirdly, Les et al. (1991) point out that the high levels of genetic load likely to be maintained in self-incompatible species and expressed when they produce selfed seed may represent a genetic constraint on selection for selfcompatible individuals.

Correlations of outcrossed paternity are subject to appreciable standard errors and should be interpreted cautiously. However, two general points can be made from the present estimates. First, the mean $r_{\mathrm{p}}$-values of both Daviesia species are similar, despite their overall differences in population size, density and geographical isolation. Secondly, for D. mimosoides, population size and density appear to be negatively related to $r_{\mathrm{p}}$, meaning that the chance of producing outcrossed full-sibs is increased in small sparse populations.

There are several possible explanations for this result. First, the reduced number of potential fathers in smaller populations may directly increase the correlation of outcrossed mating events. Secondly, the effect may relate to the influence of population size and density on pollinator behaviour. If low densities of flowering plants promote pollinator movements within a plant and reduce those between plants, the likelihood of a pair of flowers on the same plant receiving the same outcross pollen will be increased. Certainly, the effects of flowering plant density on both pollinator behaviour and mating system parameters have been reported previously. For example, Karron et al. (1995) found that both the proportion of interplant pollinator flights and the frequency of outcrossing increased with higher population density in experimental populations of Mimulus ringens. A final possible explanation follows from the negative relationships between population size and the degree of divergence in allele frequencies between the pollen and population gene pools as measured by $F_{\mathrm{c}}$ and $F_{\mathrm{k}}$ (Fig. 1 and Table 3 ). These show that, as a population shrinks, the pollen gene pool becomes a less representative sample of the population gene pool. Therefore, in smaller populations, not only are there fewer potential 
fathers, but these fathers are also contributing less evenly to the pollen pool than is the case in larger populations.

The great variation in estimates of single-plant outcrossing rates for both $D$. suaveolens and $D$. mimosoides is inconsistent with the high populationlevel estimates and the near-total lack of selfcompatibility for both species. The general lack of correlation between $t_{\mathrm{ms}}$ and measures of plant size or

(a) D. sauveolens

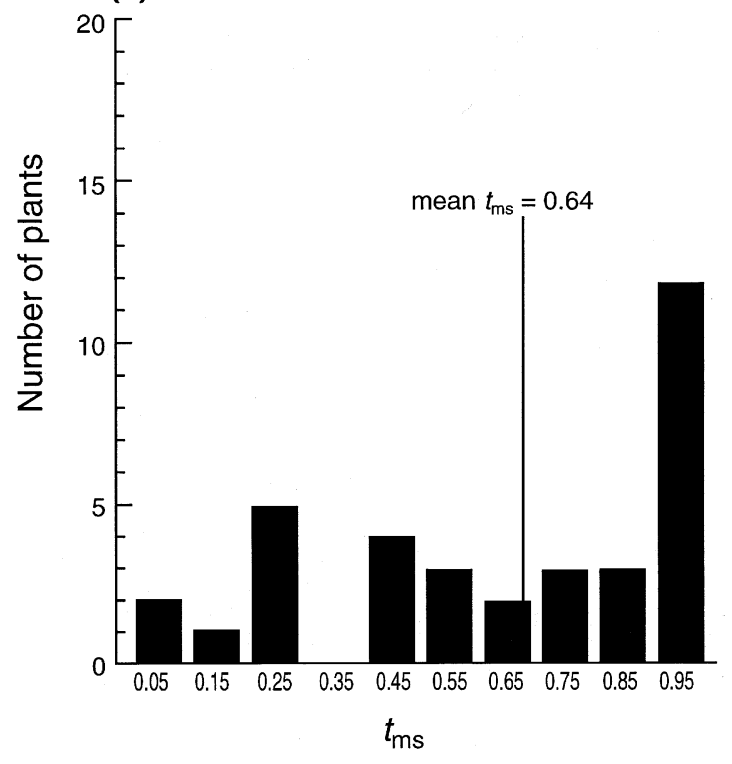

(b) D. mimosoides

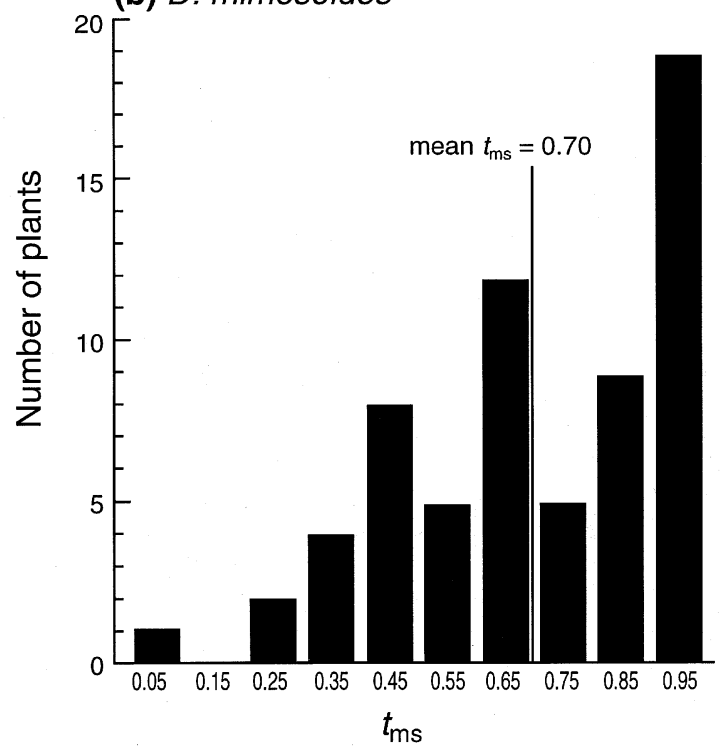

Fig. 2 Frequency distributions and means of single-plant outcrossing rates $\left(t_{\mathrm{ms}}\right)$ over all populations for (a) Daviesia suaveolens and (b) D. mimosoides.

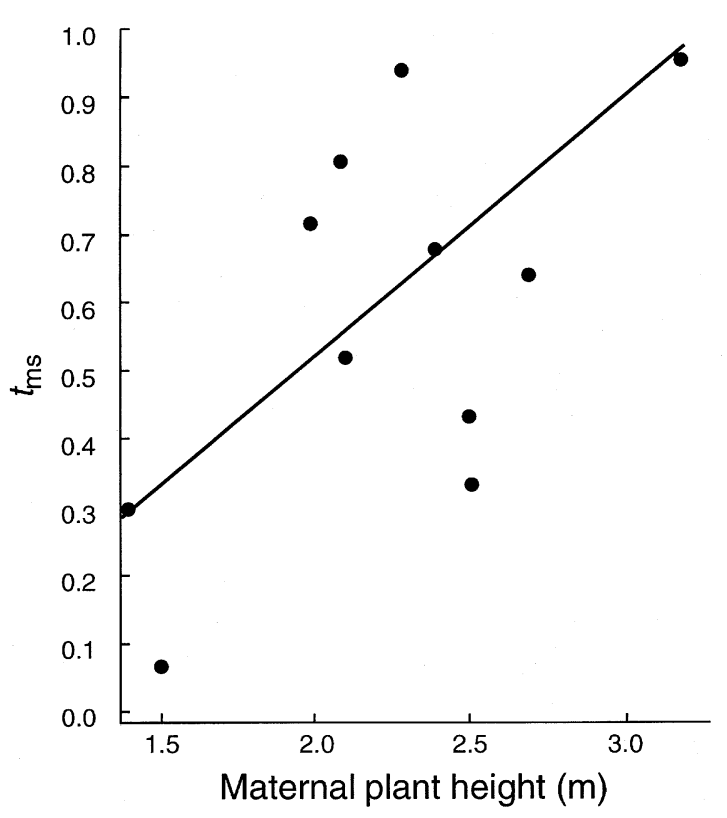

Fig. 3 Relationship between maternal plant height and multilocus single-plant outcrossing rate $\left(t_{\mathrm{ms}}\right)$ for the Daviesia mimosoides Boomanoomana population. $R^{2}=0.37$, $P<0.05$.

local flowering environment suggests that these parameters have little effect on mating events within populations or that the measures chosen in fact reflect these parameters rather poorly.

Estimates of single-plant rates are less robust to the influences of sampling error, biparental inbreeding and correlated mating than are population level estimates. They can also be strongly affected by the influence of maternal genotype and population marker diversity on the probability of detecting outcrosses. That the distribution of $t_{\mathrm{ms}}$ estimates for D. suaveolens maternal plants was more dispersed than that for $D$. mimosoides plants may reflect the lower average gene diversity and, hence, outcross detectability for the rare species $\left(H_{\mathrm{e}}=0.28\right)$ compared with the common one $\left(H_{\mathrm{e}}=0.41\right)$. This possibility is supported by the negative relationship observed between population gene diversity and population variance for $t_{\mathrm{ms}}$ when the eight populations were analysed together. That there were no corresponding effects of maternal heterozygosity on either $t_{\mathrm{ms}}$ or its variance may be because allelic identity also influences outcross detectability, which this analysis did not take into account. Given these results, it is likely that most of the observed variation in single-plant outcrossing rates reflects the combined effects of sampling error, correlated mating and the influence of marker diversity on outcross detectability, rather than variation in actual

(c) The Genetical Society of Great Britain, Heredity, 80, 374-381. 
selfing rates caused by among-plant differences in self-compatibility, phenology or size.

These results have implications for the conservation and management of $D$. suaveolens. Its strong self-incompatibility system means that even small populations are currently almost fully outcrossed and are under little threat from inbreeding depression. However, if further reductions in population size lead to changes in patterns of outcrossed mating so as to produce more full-sibs within progeny arrays, as was apparently observed for D. mimosoides, future generations would be prone to inbreeding as these closely related plants begin to mate. If populations crash or habitat deteriorates such that populations no longer attract or support suitable pollinators, the situation will be more critical. Under this scenario, the inability of $D$. suaveolens to reproduce autogamously, vegetatively or by agamospermy could lead to population extinction.

\section{Acknowledgements}

L. Spindler, J. West and M. Kilby assisted with pollinations and L. Gregory assisted with electrophoretic analyses. G. Clarke identified bee pollinators. The Australian Capital Territory Parks and Conservation Service, the New South Wales National Parks Service and the Department of Conservation and Natural Resources of Victoria provided permits for seed collection.

\section{References}

ADAMS, w. T. 1992. Gene dispersal within forest tree populations. New Forests, 6, 217-240.

BAKER, H. G. 1955. Self-compatibility and establishment after long-distance dispersal. Evolution, 9, 349-350.

BROWN, A. H. D. AND ALlARD, R. W. 1970. Estimation of the mating system in open-pollinated maize populations using isozyme polymorphism. Genetics, 66, 133-145.

BROWN, A. H. D. AND MARSHALl, D. R. 1995. A basic sampling strategy: theory and practice. In: Guarino, L., Rao, V. R. and Reid. R. (eds) Collecting Plant Genetic Diversity Technical Guidelines, pp. 75-90. CAB International, Wallingford, Oxon.

CRISP, M. D. 1991. Contributions towards a revision of Daviesia Smith (Fabaceae: Mirbelieae). II. The D. latifolia group. Aust. Syst. Bot., 4, 229-298.

DEMAURO, M. M. 1993. Relationship of breeding system to rarity in the Lakeside daisy (Hymenoxys acaulis var. glabra). Conserv. Biol., 7, 542-550.
Ellstrand, N. C., TORRES, A. M. AND LEVIN, D. A. 1978. Density and the rate of apparent outcrossing in Helianthus annuus (Asteraceae). Syst. Bot., 3, 403-407.

FRANKEL, O. H., BROWN, A. H. D. AND BURDON, J. J. 1995. The Conservation of Plant Biodiversity. Cambridge University Press, Cambridge.

KARRON, J. D. 1989. Breeding systems and levels of inbreeding depression in geographically restricted and widespread species of Astragalus (Fabaceae). Am. J. Bot., 76, 331-340.

KARRoN, J. D. 1991. Patterns of genetic variation and breeding systems in rare plant species. In: Falk, D. A. and Holsinger, K. E. (eds) Genetics and Conservation of Rare Plants, pp. 87-98. Oxford University Press, Oxford.

KARRON, J. D., THUMSER, N. N., TUCKER, R. AND HESSENAUER, A. J. 1995. The influence of population density on outcrossing rates in Mimulus ringens. Heredity, 75, $175-180$.

LES, D. H., REINARTIZ, J. A. AND ESSELMAN, E. J. 1991. Genetic consequences of rarity in Aster furcatus (Asteraceae), a threatened, self-incompatible plant. Evolution, 45, 1641-1650.

MURAWSKI, D. A., GUNATILLEKE, I. A. U. N. AND BAWA, K. S. 1994. The effects of selective logging on inbreeding in Shorea megistophylla (Dipterocarpaceae) from Sri Lanka. Conserv. Biol., 8, 997-1002.

RITLAND, K. 1989. Correlated matings in the partial selfer Mimulus guttatus. Evolution, 43, 848-859.

RITLAND, K. 1994. MLTR Multilocus mating system program Version 0.9. Available from author.

RITLAND, K. AND JAIN, s. K. 1981. A model for the estimation of outcrossing rate and gene frequencies using $n$ independent loci. Heredity, 47, 35-52.

SCHEMSKE, D. W. AND LANDE, R. 1985. The evolution of self-fertilisation and inbreeding depression in plants. II. Empirical observations. Evolution, 39, 41-52.

STEBbins, G. L. 1957. Self-fertilisation and population variability in the higher plants. Am. Nat., 91, 337-354.

WAPLES, R. s. 1989. A generalized approach for estimating effective population size from temporal changes in allele frequency. Genetics, 121, 379-391.

WATKINS, L. AND LEVIN, D. A. 1990. Outcrossing rates as related to plant density in Phlox drummondii. Heredity, 65, 81-89.

WEIR, B. S. 1990. Genetic Data Analysis. Sinauer Associates, Sunderland, MA.

YEH, F. C. AND BOYLE, T. J. B. 1997. POPGENE Version 1.1, CIFOR, Bogor.

YOUNG, A. G. AND BROWN, A. H. D. 1996. Comparative population genetic structure of the rare woodland shrub Daviesia suaveolens and its common congener D. mimosoides. Conserv. Biol., 10, 1220-1228. 